\title{
Analysis of a Health Team's Records and Nurses' Perceptions Concerning Signs and Symptoms of Delirium ${ }^{1}$
}

\author{
Rosa Carla Gomes da Silva² \\ Abel Avelino de Paiva e Silva ${ }^{3}$ \\ Paulo Alexandre Oliveira Marques ${ }^{4}$
}

This study investigates the extent of under-diagnosis of acute confusion/delirium by analyzing the records of a health team and the perception of nurses concerning this phenomenon. This quantitative study was developed in a central university hospital in Portugal and used the documentary and interview techniques. The sample obtained through the application of the NeeCham's scale was composed of 111 patients with the diagnosis of acute confusion/ delirium hospitalized in the medical and surgical acute care units. A rate of $12.6 \%$ of underdiagnosis was identified in the records and a rate of $30.6 \%$ was found taking into account the perception of nurses. No indicators of acute confusion/delirium were found in $8.1 \%$ of the 111 cases and only $4.5 \%$ of the patients were diagnosed with acute confusion/ delirium. The results indicate there is difficulty in identifying acute confusion/delirium, with implications for the quality of care, suggesting the need to implement training measures directed to health teams.

Descriptors: Nursing; Elderly; Delirium, Dementia, Amnestic, Cognitive Disorders.

\footnotetext{
${ }^{1}$ Paper extracted from Master's Dissertation "Confusão: A Dimensão do Subdiagnóstico" presented to Instituto Superior de Saúde, Universidade Católica Portuguesa, Porto, Portugal.

2 RN, M.Sc. in Nursing, Instituto Português de Oncologia Francisco Gentil do Porto, Portugal. E-mail: rosa_silva33@hotmail.com.

${ }^{3}$ RN, Ph.D. in Nursing, Professor Coordinator, Escola Superior de Enfermagem do Porto, Portugal. E-mail: abel@esenf.pt.

${ }^{4}$ RN, M.Sc. in Nursing Science, Adjunct Professor, Escola Superior de Enfermagem do Porto, Portugal. E-mail: paulomarques@esenf.pt.
}

Corresponding Author:

Abel Avelino de Paiva e Silva

Escola Superior de Enfermagem do Porto

Rua Dr. António Bernardino de Almeida, s/n

4200-072 Porto, Portugal

E-mail:abel@esenf.pt 


\title{
Análise dos registros produzidos pela equipe de saúde e da percepção dos enfermeiros sobre os sinais e sintomas de delirium
}

Esta pesquisa pretendeu conhecer a dimensão do subdiagnóstico da confusão aguda/ delirium, ao analisar os registros produzidos pela equipe de saúde e percepção dos enfermeiros sobre esse fenômeno. Foi desenvolvido em um hospital universitário central, de Portugal, delineada dentro do paradigma quantitativo, utilizando a técnica documental e entrevista. A amostra obtida, pela aplicação da Escala de Confusão NeeCham, foi de 111 doentes com diagnóstico de confusão aguda/delirium, internados em unidades de cuidados agudos médicos e cirúrgicos. Identificou-se taxa de subdiagnóstico do fenômeno de $12,6 \%$ nos registros e de $30,6 \%$ tendo em conta a percepção dos enfermeiros. Em $8,1 \%$, dos 111 casos, não foi identificado qualquer indicador de confusão aguda/ delirium. Somente $4,5 \%$ dos doentes tinha o fenômeno diagnosticado. Os resultados apontam dificuldade para se identificar a confusão aguda/delirium, com implicações para a qualidade dos cuidados, sugerindo a necessidade de medidas formativas dirigidas às equipes de saúde.

Descritores: Enfermagem; Idosos; Delirium, Demência, Transtorno Amnéstico e outros Transtornos.

\section{Análisis de registros producidos por el equipo de salud y de la percepción de los enfermeros sobre las señales y síntomas de delirio}

\begin{abstract}
Esta investigación pretendió conocer la dimensión del subdiagnóstico de la confusión aguda/delirio, al analizar los registros producidos por el equipo de salud y percepción de los enfermeros sobre este fenómeno. Fue desarrollado en un hospital universitario central de Portugal. Delineada dentro del paradigma cuantitativo, utilizando la técnica documental y la entrevista. La muestra obtenida, por la aplicación de la Escala de Confusión NeeCham, fue de 111 enfermos con diagnóstico de confusión aguda/delirio, internados en unidades de cuidados agudos médicos y quirúrgicos. Se identificó una tasa de subdiagnóstico del fenómeno de $12,6 \%$ en los registros y de $30,6 \%$ teniendo en cuenta la percepción de los enfermeros. En 8,1\% de los 111 casos, no fue identificado cualquier indicador de confusión aguda/delirio. Solamente, 4,5\% de los enfermos tenían el fenómeno diagnosticado. Los resultados apuntan para la dificultad en identificar la confusión aguda/delirio, con implicaciones para la calidad de los cuidados, sugiriendo la necesidad de adoptar medidas formativas dirigidas a los equipos de salud.
\end{abstract}

Descriptores: Enfermería; Ancianos; Delirium, Demencia, Amnésicos y Cognitivos.

\section{Introduction}

Acute Confusion (AC) is frequently described as Acute Confusional State (ACS) or delirium(1-3). However, some caveats are found in the literature. AC/ACS are labels frequently used and people tend to identify this clinical condition through the responses given to these episodes. The concept of delirium most strictly defined is based on the Diagnostic and Statistical Manual of Mental Disorders presented by the Psychiatric Association (APA)(3).
The APA characterizes delirium as reduced consciousness manifested by cognitive, orientation, memory, attention, thinking or behavior disorders, also involving errors in sensorial perception ${ }^{(4)}$. This syndrome is more frequently found among elderly hospitalized individuals ${ }^{(1-5)}$ than among individuals in other age groups $^{(6)}$, and holds a high clinical interest because it is related to less favorable health results, increased cases of dementia, morbidity, mortality, time 
of hospitalization and the costs associated with it ${ }^{(1-5)}$. It has a multifactorial cause and is usually associated with predisposing factors (visual impairment, severe disease) and precipitant ones (immobility, poor nutrition) $)^{(1,3,5)}$. Despite its importance, the evidence shows it remains under-diagnosed in about $25 \%$ to $75 \%$ of the cases, reaching $100 \%$ in its hypoactive subtype ${ }^{(5)}$, which is more difficult to recognize ${ }^{(7-8)}$. The fluctuating nature of its manifestations coupled with health professionals' lack of knowledge concerning this syndrome's characteristics, the low use of evaluation instruments to monitor it(5,9-11) - such as the NeeCham Confusion Scale(11) - and lack of recording the phenomenon on the part of the health team, are other reasons leading to its under-diagnosis. Because nurses are constantly in contact with patients, they are in a better position to detect subtle changes early and diagnose the problem. If this condition remains under-diagnosed it is not treated ${ }^{(2-3,7,9)}$ and can result in innumerous personal, social and economic(8) consequences. Therefore, investigating this issue is considered a priority.

This study's general objective was to identify the level of under-diagnosis of $\mathrm{AC} /$ delirium in a central university hospital in Portugal. Its specific objectives were: to identify the level of severity of AC/delirium; analyze the proportion of indicators (signs and symptoms) of $\mathrm{AC} /$ delirium in the records kept by physicians and nurses at the clinical level through the descriptions that indicate the phenomenon or related interventions; and analyze the nurses' level of perception concerning the phenomenon of $\mathrm{AC} /$ delirium.

This study also explored the relationship between the characteristics of patients and of hospitalization with the documentation of the phenomenon, documentation of nursing interventions, nurses' perceptions and underdiagnosis of $\mathrm{AC} /$ delirium, aiming to find the causes, besides those already known, that might explain its under-diagnosis.

\section{Method}

This is a non-experimental, exploratory and correlational descriptive study with a quantitative approach, a method that allows an objective description of historical facts. It was conducted at the hospital of the University of Coimbra, which is composed of various buildings with diverse medical specialties and cares for a large number of patients. The exclusion criteria were: being hospitalized for less than 24 hours; being younger than 17 years old; having concurrent psychiatric diagnosis or aphasia. A non-probabilistic convenience sample was used and the Portuguese version of the NeeCham Confusion Scale ${ }^{(11)}$ validated for the Portuguese culture was applied; this is a good instrument to evaluate the studied phenomenon ${ }^{(3)}$.

The services available for data collection were the following units: medicine, cardiology, surgery, endocrinology, gastroenterology, hematology, neurology, orthopedics, pneumology, intensive therapy, infectology and urology. Cross-sectional data collection was carried out over two months and a sample of 111 patients was obtained. The selected patients were those who obtained scores below 25 on the NeeCham Confusion Scale.

A documentary analysis was performed in the clinical processes of the 111 patients (medical and nursing records) and the nurses responsible for caring for these patients were interviewed immediately after the NeeCham Confusion Scale was applied. The following question guided the interview: how do you evaluate your patient's mental condition? Answers provided the nurses' perceptions concerning the phenomenon. The documentary analysis aimed to quantify the level of under-diagnosis of the phenomenon given the presence of diagnosis, signs and symptoms. The interview aimed to unveil the nurses' perceptions concerning the presence of $\mathrm{AC} /$ delirium at that point in time. A total of 111 interviews were conducted, one per patient, while some nurses had more than one patient in this condition.

The analysis of collected data, clinical records and interviews was based on the technique of content analysis(12). For that, an analysis model was initially conceived. It was composed of categories and dimensions listed in the literature as indicators of AC/delirium based on the International Classification for Nursing Practice ${ }^{\circledR}$ version $1.0^{(13)}$. The method used to organize the corpus of analysis within the established categories was guided by the semantic value. The semantic value was the base unit from which information was categorized; each unit was recorded in each dimension only once ${ }^{(12)}$. Hence, it was a categorical, frequency and quantitative analysis. Data were analyzed by the Statistical Package for the Social Sciences - version 14.0. Descriptive and inferential statistics were used in order to provide richer information.

The study was approved by the Research Ethics Committee after it was submitted to and authorized by the directors and managers of the nursing units (Doc. no. 111). Because the confused patients were considered vulnerable individuals, their legal/family representatives were asked to sign free and informed consent forms. The nurses also signed free and informed consent forms in order to participate in the study. 


\section{Results}

\section{General Data}

The obtained results indicate that the 111 patients (with AC/delirium) were between 23 and 96 years of age, with an average age of 75.6 years. About half (56.8\%) were between 65 and 84 years old, and $52.3 \%$ were men. Patients were hospitalized for an average of 12.2 days. According to the NeeCham Confusion Scale (this scale also reveals the condition's level of severity), 59.5\% presented the highest level of severity - moderate to severe confusion. The remaining 40.5\% displayed mild or early development of confusion. The individuals were distributed in the different units. A total of $69.3 \%$ belonged to three types of units: medicine (39.6\%); neurology (19.8\%) and orthopedics (9.9\%). In terms of medical diagnosis, the largest groups were the circulatory system ( $26.1 \%)$, followed by the respiratory tract $(22.5 \%)$, and neoplasms $10.8 \%$.

\section{Documentation of the phenomenon}

The diagnosis of $\mathrm{AC} /$ delirium was identified in $4.5 \%(n=5)$ of the 111 patients in the sample.
However, the clinical records allowed the identification of various indicators of $\mathrm{AC} /$ delirium, which were called documentation of the phenomenon.

The documentation of the phenomenon, the result of analyzing the hospital records of patients with $\mathrm{AC} /$ delirium, fit in the categories: psychological process, behavior, body process, neurological status, ability and other dimensions associated with the phenomenon. Based on this conception, the phenomenon was documented in $86.5 \%$ of the cases, hence, under-diagnosis of the documentation of the phenomenon was identified in $13.5 \%$ of the cases.

A total of 504 descriptors were identified and these can be related to AC/delirium, especially in the nurses' records. The most frequent are the $31.9 \%$ that refer to neurological status, the $21.7 \%$ that refer to body process, the $18.2 \%$ that refer to psychological process; the $17.5 \%$ that refer to behavior, and the $10.7 \%$ that refer to alterations at other levels as presented in Table 1.

According to the adopted classification, confusion is a type of cognition, which in turn is a psychological process at a higher and abstract level(13).

Table 1 - Descriptors of AC/delirium

\begin{tabular}{|c|c|c|}
\hline \multicolumn{3}{|c|}{ Category - Psychological Process } \\
\hline Dimension & Unit of Record & $\mathbf{N}(\%)$ \\
\hline \multicolumn{3}{|l|}{ Cognition } \\
\hline Confusion & 'continues with periods of confusion' & $47(9.3)$ \\
\hline Attention & 'rarely fixes the gaze' & $14(2.8)$ \\
\hline Aphasia & 'maintains aphasia' & $20(3.9)$ \\
\hline \multicolumn{3}{|l|}{ Attitude } \\
\hline Denial & 'refused any treatment' & $2(0.4)$ \\
\hline \multicolumn{3}{|c|}{ Category - Behavior } \\
\hline Dimension & Unit of Record & $\mathbf{N}(\%)$ \\
\hline Interactive behavior & 'pulled out the nasograstic tube' & $69(13.7)$ \\
\hline Self Performing Activity & 'attempted many times to get out of the bed' & $19(3.8)$ \\
\hline \multicolumn{3}{|c|}{ Category - Body process } \\
\hline Dimension & Unit of Record & $\mathbf{N}(\%)$ \\
\hline \multicolumn{3}{|l|}{ Rest } \\
\hline Sleep & 'intermittent and brief sleep' & $17(3.4)$ \\
\hline \multicolumn{3}{|l|}{ Nervous system process } \\
\hline Psychomotor activity & 'was agitated during the entire shift' & $74(14.7)$ \\
\hline Disorganized behavior & ‘inconsistent behavior’ & $12(2.4)$ \\
\hline Perception & 'auditory hallucinations' & $6(1.2)$ \\
\hline \multicolumn{3}{|c|}{ Category - Neurological status } \\
\hline Dimension & Unit of Record & $\mathbf{N}(\%)$ \\
\hline Alertness & ‘vacant, lost stare' & $11(2.2)$ \\
\hline Consciousness & 'altered state of consciousness' & $57(11.3)$ \\
\hline Orientation & 'disorientation in time and space' & $58(11.5)$ \\
\hline Response & 'apathetic' & $35(6.9)$ \\
\hline
\end{tabular}


Table 1 - (continuation)

\begin{tabular}{lcc}
\hline \multicolumn{1}{c}{ Dimension } & Category - Ability & \\
Unit of record & N (\%) \\
\hline Ability to communicate & 'verbose, incoherent speech or indistinguishable' & $49(9.7)$ \\
Others & & $14(2.8)$ \\
Total & & $504(100)$ \\
\hline
\end{tabular}

In relation to the concepts associated with the description of the conditions of patients with AC/delirium the dimensions psychomotor activity, confusion, interactive behavior, consciousness, orientation, and ability to communicate, together represent $70.2 \%$ of data, while about one third $(31.9 \%)$ is in the category neurological status.

The patients with documentation of phenomenon are on average hospitalized for longer periods and display more severe $\mathrm{AC} /$ delirium $(\mathrm{t}=-1.532$ and $p=0.005$; $\mathrm{t}=2.918$ and $p=0.004$ ). There is also a statistically significant relationship with hospitalization service $\left(X^{2}=18.898\right.$ and $\left.p=0.042\right)$. The phenomenon is better documented in the medicine, neurology and orthopedics services.

\section{Documentation of nursing interventions}

The analysis sought to identify documentation of nursing interventions reveals a total of 134 interventions (Table 2). Most (67.9\%) of them are in the domain organization, for example: immobilizing with other device was the most common intervention followed by immobilizing with bed rail. Of the 111 patients, only 66 were subjected to interventions somewhat related to the phenomenon, which indicates that $40.5 \%$ of the patients did not receive interventions.

Table 2 - Descriptors of nursing interventions

\begin{tabular}{|c|c|c|}
\hline \multicolumn{3}{|c|}{ Category - Prevent } \\
\hline Actions & Care & $\mathbf{N}(\%)$ \\
\hline \multicolumn{3}{|l|}{ Protect } \\
\hline Fall prevention & 'evaluate measures of physical and mechanical restraint' & $1(0.8)$ \\
\hline Safety measures & 'ensure and maintain physical integrity' & $1(0.8)$ \\
\hline \multicolumn{3}{|c|}{ Category - Organize } \\
\hline Actions & Care & $\mathbf{N}(\%)$ \\
\hline \multicolumn{3}{|l|}{ Control } \\
\hline Immobilizing with bed rail & 'protective side rails were applied on bed' & $42(31.3)$ \\
\hline Immobilizing with other device & 'upper limbs were immobilized’ & $49(36.6)$ \\
\hline \multicolumn{3}{|c|}{ Category - Assist } \\
\hline Actions & Care & $\mathbf{N}(\%)$ \\
\hline Promote communication & 'speak directly and slowly, giving time for the patient to answer' & $6(4.5)$ \\
\hline Others & & $35(26)$ \\
\hline Total & & $134(100)$ \\
\hline
\end{tabular}

The documentation of nursing interventions reveals there is a statistically significant difference for the level of severity of $\mathrm{AC} /$ delirium ( $\mathrm{t}=2.148 ; p=0.029)$, since patients with documentation of interventions display, on average, more severe AC/delirium. A significant relationship was found with documentation of interventions in relation to gender and hospitalization service $\left(X^{2}=6.355\right.$ and $p=0.012 ; X^{2}=23.205$ and $p=0.010)$. In the cases without documentation of interventions, $62.2 \%$ were women and $37.8 \%$ were men. A low frequency of documentation of intervention was identified in the surgery and urology services: $100 \%$ and $85.7 \%$, respectively, did not have documentation of nursing interventions.

The results also permitted verifying that the documentation of the phenomenon is significantly related to the documentation of interventions $\left(X^{2}=20.053\right.$ and $p \leq 0.001$ ), since most of the patients with documentation 
of the phenomenon also have documentation of nursing interventions. Table 3 shows that among patients without documentation of the phenomenon, only one had documentation of interventions.

Table 3 - Relationship between documentation of the phenomenon and documentation of nursing interventions

\begin{tabular}{lcccc}
\hline & & \multicolumn{3}{c}{$\begin{array}{c}\text { Documentation of the } \\
\text { phenomenon }\end{array}$} \\
\cline { 3 - 5 } & & No & Yes & Total \\
\cline { 3 - 5 } & no & $14(31.1)$ & $31(68.9)$ & $45(100)$ \\
& yes & $1(1.5)$ & $65(67.7)$ & $96(100)$ \\
Documentation of nursing & & $\mathbf{n}(\%)$ & $\mathbf{n}(\%)$ & $\mathbf{n}(\%)$ \\
interventions & & $15(13.5)$ & $96(86.5)$ & $111(100)$ \\
\hline
\end{tabular}

\section{Extent of under-diagnosis of confusion in documentation}

According to the data, $12.6 \%$ of patients did not present any documentation of the phenomenon or documentation of interventions; hence this is the value of under-diagnosis in the documentation. The relationships between documentation of the phenomenon and documentation of interventions presented in Table 4 are evidence of the importance of identifying the phenomenon.

Table 4 - Relations between documentation of the phenomenon and documentation of interventions

\begin{tabular}{lc}
\hline \multicolumn{1}{c}{ Documentation } & N (\%) \\
\hline $\begin{array}{l}\text { With documentation of the phenomenon but without } \\
\text { documentation of interventions }\end{array}$ & $31(28)$ \\
$\begin{array}{l}\text { With documentation of the phenomenon and } \\
\text { documentation of interventions }\end{array}$ & $65(58.5)$ \\
$\begin{array}{l}\text { No documentation of the phenomenon but with } \\
\text { documentation of interventions }\end{array}$ & $1(0.9)$ \\
$\begin{array}{l}\text { No documentation of the phenomenon and no } \\
\text { documentation of interventions }\end{array}$ & $14(12.6)$ \\
Total & $111(100)$ \\
\hline
\end{tabular}

A statistically significant relationship was found between the hospitalization service and under-diagnosis of $\mathrm{AC} /$ delirium in the documentation $\left(X^{2}=19.007\right.$ and $p=0.040)$. The urology service was the service that presented the highest level of under-diagnosis: $57.1 \%$ of its patients did not present documentation of the phenomenon or documentation of interventions. The relation of under-diagnosis with the phenomenon's severity was also significant ( $t=2.904 ; p=0.004)$, noting that the under-diagnosed cases are, on average, less severe.

\section{Perceptions of nurses}

The interviews with nurses showed that $30.6 \%$ of them did not identify AC/delirium. A total of 131 associated concepts were identified among the nurses who identified the phenomenon. These concepts gave origin to the same categories used in the documentation of the phenomenon, only with different frequencies. A total of $36.6 \%$ of the concepts referred to the category neurological status, $32.8 \%$ to the psychological process and $15.4 \%$ to body process, and $9.2 \%$ and $6.1 \%$ to behavior and ability, respectively. The dimension that obtained the highest number of answers was orientation (29.0\%), followed by confusion with $24.4 \%$.

The perception of nurses was significantly related to the degree of severity of $\mathrm{AC} /$ delirium ( $\mathrm{t}=5.397$ and $p$ $<0.001$ ) and also with the degree of documentation of the phenomenon $\left(x^{2}=7.041\right.$ and $\left.p=0.008\right)$, noting that the more severe patients were more easily identified and also that $92.2 \%$ of the patients with documentation of the phenomenon were identified by the nurses as having AC/delirium.

\section{Absolute under-diagnosis of $\mathrm{AC} /$ delirium}

Data suggest that the absolute magnitude of underdiagnosis is $8.1 \%$; that is, no indicator related to $\mathrm{AC} /$ delirium was found in the documentation (phenomenon or interventions) or in the perception of nurses. When the phenomenon is recognized, the patients are older on average and present a greater level of severity of $\mathrm{AC} /$ delirium ( $\mathrm{t}=-2.400$ and $p=0.018 ; \mathrm{t}=3.412$ and $p=0.01$, respectively). The absolute under-diagnosis of $A C /$ delirium is also significantly related to under-diagnosis in the documentation $\left(X^{2}=67.859\right.$ and $p<0.001$ ) (Table 5).

Table 5 - Relationship between total under-diagnosis and under-diagnosis in the documentation

\begin{tabular}{lcccc}
\hline & & \multicolumn{3}{c}{$\begin{array}{c}\text { Under-diagnosis of } \\
\text { AC/delirium }\end{array}$} \\
& & No & Yes & Total \\
\cline { 3 - 5 } & & $\mathbf{n}(\%)$ & $\mathbf{n}(\%)$ & $\mathbf{n}(\%)$ \\
\hline $\begin{array}{l}\text { Under-diagnosis in the } \\
\text { documentation }\end{array}$ & no & $97(100)$ & $0(0)$ & $97(100)$ \\
Total & yes & $5(35.7)$ & $9(64.5)$ & $14(100)$ \\
\hline & & $102(91.9)$ & $9(8.1)$ & $111(100)$ \\
\hline
\end{tabular}




\section{Discussion}

Most of the documentation related to patients with $\mathrm{AC} /$ delirium emerges from the documentation performed by nurses, which is consistent with the literature. Given the most intense contact of nurses with patients, nurses are able to more rapidly identify changes in patients' mental conditions ${ }^{(1,3,14)}$. However, establishing the diagnosis is difficult( ${ }^{(5,8-9)}$ and may be related to the syndrome's characteristics (fluctuation of symptoms and the hypoactive subtype), infrequent use of reliable evaluation instruments, and factors inherent to the nurses themselves ${ }^{(9-11)}$. As the data show, the characteristics of patients with $\mathrm{AC} /$ delirium (age and gender) and the particularities of the hospitalization (service and time of hospitalization) can also influence the recognition of the phenomenon and the conception of nursing care.

The study confirmed that a large portion of patients with $\mathrm{AC} /$ delirium are elderly, which is in agreement with the literature ${ }^{(1-5,9-11,15)}$. This age group tends to have a set of conditions that favors the development of this syndrome due to these individuals' vulnerability and also due to their more active use of health services ${ }^{(16)}$. They have also lived more years with more weaknesses. At the same time, more than two thirds of these patients were concentrated in three types of service - medical, orthopedics and neurological - that are already known to be related to a set of prevalent pathologies (such as the diseases in the circulatory system and respiratory tract) and the characteristics inherent to this age group ${ }^{(2,17)}$.

Documentation of the phenomenon was identified in about $86 \%$ of the clinical records and is related to hospitalization service and time, severity of $\mathrm{AC} /$ delirium and documentation of nursing interventions. The professionals of services that have a frequency of patients with $\mathrm{AC} /$ delirium above the average are more familiar with the phenomenon and are able to observe it better. Longer hospitalizations advance identification of the phenomenon. When professionals spend more time with patients they improve their knowledge of them and become more able to detect changes in their mental condition, increasing opportunities to document it.

$\mathrm{AC} /$ delirium is primarily identified through clinical indicators of exacerbation of motor behavior such as the exteriorization of medical devices, attempt to get out of the bed, which often results in falls and has been confirmed by evidence $^{(18)}$. It is known that many elderly patients have the hypoactive subtype that is more difficult to detect, unlike patients who have more expressive signs and symptoms; the hyperactive subtype is more easily detected. This study's concept of severity is in agreement with data from the literature and seems to be strongly related to the hyperactive subtype ${ }^{(7-8)}$. Hence, the conclusion is that under-diagnosis of $\mathrm{AC} /$ delirium is mainly present is cases of lethargy, sleepiness, or apathy.

The existence of documentation but with absence of perception of the phenomenon was identified, which may indicate a lack of understanding on the part of nurses concerning the specificities of this syndrome. Attention deficit is one of the most common changes distinguishing $\mathrm{AC} /$ delirium $^{(10,19)}$ and a reduced number of cases was identified in this study. Additionally, indicators of rapid onset and fluctuation of symptoms were never recorded in the analyzed documentation. The literature also indicates that nurses have deficient knowledge related to geriatrics ${ }^{(20-21)}$ and $A C /$ delirium $^{(10-11)}$, which might explain the lack of records of this phenomenon's characteristics.

The documentation of nursing interventions is related to the documentation of the phenomenon and to the patients' gender. The first aspect seems logical. There is a higher probability of a patient to undergo nursing interventions once the problem is identified. However, the gender aspect is more of a problem since male patients are more susceptible to the development of this phenomenon and this fact may be related to potential beliefs and stereotypes. It is important to keep in mind that a significant number of interventions are related to behavior control measures, which may indicate more hyperactivity manifestations on the part of male patients and explain the restraint measures. The truth is that these interventions per se represent a risk factor for AC/delirium and indicate the poor quality of care delivery(22). Nursing practices should go beyond the simple management of signs and symptoms ${ }^{(23)}$, as in the case of physical restraint. Hence, this study's findings require professionals to reflect on why interventions considered important in the literature, such as reality orientation $^{(5,9-10)}$, are not documented and the following question is posed: is it possible that interventions are planned but not recorded, or that they are undervalued or unknown? The fact that about one third of the patients with documentation of phenomenon did not have any documentation of nursing interventions is of concern.

The hospitalization service was an element that influenced the documentation of the phenomenon and documentation of interventions. The urology, hematology and surgery services displayed significantly higher rates of under-diagnosis in documentation than other units. 
Perhaps, the professionals working in these units are less attentive to the phenomenon given its lower incidence in these units.

Age is an important factor in the under-diagnosis issue because the older the individual the lower is underdiagnosis of AC/delirium, a factor already described in another study(24). Although age is associated with $\mathrm{AC} /$ delirium, any inpatient is susceptible to this syndrome ${ }^{(1,6,15)}$.

Even though an absolute rate of $8.1 \%$ of $\mathrm{AC} /$ delirium under-diagnosis was identified, it is a less expressive rate compared with data from other studies $(7,14,16)$. When one broadens the concepts and includes indicators of altered mental condition, under-diagnosis substantially decreases. On the other hand, when only the concepts $\mathrm{AC}$ and/or delirium are considered at the level of clinical process, only $4.5 \%$ of the cases were diagnosed, which reveals under-diagnosis rates that are truly of concern. Additionally, if only the concept delirium was taken into account, which was observed only once in the medical records, the under-diagnosis rate would be virtually $100 \%$. Therefore, the fact that this investigation enabled the identification of concepts or indicators indicating the phenomenon does not mean the professionals confirmed the diagnosis. Hence, under-recognition is the main problem in diagnosing $\mathrm{AC} /$ delirium $^{(5,14,16)}$.

\section{Conclusion}

This study made clear that the patients' mental condition is not properly evaluated. The use of evaluation instruments such as the NeeCham Confusion Scale is an important strategy because it makes more objective a phenomenon of great subjectivity. The under-diagnosis of $\mathrm{AC} /$ delirium is a fact and regardless of the reasons involved in its genesis, it is important to know and overcome them. This study allowed the identification of some of them, which is innovating and relevant for contributing to the knowledge in this subject. It additionally exposes the context of a large European hospital in relation to the under-recognition and underdiagnosis of $\mathrm{AC} /$ delirium, a very significant problem for the safety of patients and quality of care delivery.

Most of the documented nursing interventions refer to Physical Restraint, which is not in agreement with advanced nursing practices, though it is not clear whether other measures were implemented but not documented.

Professionals' experience should be complemented with the use of better evidence available in the literature in order to provide improved care to the population. This study opens up the possibility of implementing training measures concerning $\mathrm{AC} /$ delirium and also measures to systematically evaluate the phenomenon and nursing interventions since such measures can lead to positive results.

This study's limitations especially refer to the affected individuals because the study includes a broad set of concepts related to the phenomenon, a reduced contextualization of the study field and of the clinical experience of the involved nurses with $\mathrm{AC} /$ delirium. However, these limitations do not belittle the importance of its findings. When a professional writes the expression vacant stare, s/he may not associate it with $\mathrm{AC} /$ delirium but $\mathrm{s} /$ he has evidently identified the change in state. Relaxing the criteria would certainly increase absolute under-diagnosis, which does not diminish the quality of the findings.

\section{References}

1. Lee V. Confusion: geriatric self-learning module. Medsurg Nurs 2005; 14(1):38-41.

2. Olofsson B, Lundstro M, Borsse B, Nyberg L, Gustafson

$Y$. Delirium is associated with poor rehabilitation outcome in elderly patients treated for femoral neck fractures. Scand J Caring Sci 2005; 19(2):119-27.

3. Sendelbach S, Guthrie PT. Acute Confusion/Delirium Identification, Assessement, Treatment, and Prevention. J Gerontol Nurs 2009; 35(11):11-8.

4. American Psychiatric Association. Practice Guideline for the Treatment of Patients with Delirium. Am J Psychiatr - Supplement 1999; 156(5):1-20.

5. Tropea J, Slee J, Brand CA, Gray L, Snell T. Clinical practice guidelines for the management of delirium in older people in Australia. Austr J Ageing 2008; 27(3):150-6.

6. Waszynski CM, Petrovic K. Nurses' evaluation of the Confusion Assessment Method: a pilot study. J Gerontol Nurs 2008; 34(4):49-56.

7. Meagher D. Motor subtypes of delirium: Past, present and future. Inter Rev Psychiatr 2009; 21(1):59-73.

8. Spiller JA, Keen JC. Hypoactive delirium: assessing the extent of the problem for inpatient specialist palliative care. Palliative Med 2006; 20(1):17-23.

9. Michaud L, Büla C, Berney A, Camus V, Voellinger R, Stiefel $F$, et al. Delirium: guidelines for general hospitals. J Psychosom Res 2007; 62(3):371-83.

10. British Geriatrics Society and Royal College, of Physicians. Guidelines for the prevention, diagnosis 
and management of delirium in older people. Concise guidance to good practice series. London: RCP; 2006; (6):1-18.

11. Neelon VJ, Champagne MT, Carlson JR, Funk SG. The NEECHAM Confusion Scale: construction, validation, and clinical testing. Nurs Res 1996; 45(6):324-30.

12. Bardin L. Análise de conteúdo. Lisboa: Edições 70; 2004. 223 p.

13. Concelho Internacional de Enfermeiros. Classificação Internacional para a Prática de Enfermagem: (Versão 1.0). Genebra: International Council of Nurse; 2006. 210 p.

14. Inouye SK, Leo-Summers $L$, Zhang $Y$, Bogardus ST, Leslie DL, Agostini JV. A chart-based method for identification of delirium: validation compared with interviewer ratings using the Confusion Assessment Method. J Am Geriatr Soc 2005; 53(2):312-8.

15. Inouye SK. Delirium in older persons. N Engl J Med 2006; 354(11):1157-65.

16. Steis MR, Fick DM. Are nurses recognizing delirium? A systematic review. J Gerontol Nurs 2008; 34(9):40-8.

17. Vollmer C, Rich C, Robinson S. How to prevent delirium: a practical protocol. Nursing. 2007; 37(8):26-8.

18. Lakatos SBE, Capasso V, Mitchell MT, Kilroy SM, Lussier-Cushing $M$, Sumner $L$, et al. Falls in the general hospital: association with delirium, advanced age, and specific surgical procedures. Psychosomatics 2009; 50(3):218-26

19. Cole CS, Williams EB, Williams RD. Assessment and discharge planning for hospitalized older adults with delirium. Medsurg Nurs 2006; 15(2):71-6.

20. Voyer P, Richard S, Doucet L, Danjou C, Carmichael $P$. Detection of delirium by nurses among long-term care residents with dementia. BMC Nurs 2008; 7(4):1-14.

21. Brum A, Tocantins F, Silva $T$. The nurse as an action tool in care for the aged. Rev. Latino-Am. Enfermagem. 2005; 13(6):1019-26. doi: 10.1590/ S0104-11692005000600015. (includes abstract); Steis MR; Fick DM; Journal of Gerontological Nursing, 2008 Sep; 34 (9): 40-8

22. Siddiqi N, Holt R, Britton AM, Holmes J. Interventions for preventing delirium in hospitalised patients. Cochrane Database System Rev 2007; (2):1-44.

23. Silva AP. "Enfermagem avançada": um sentido para o desenvolvimento da profissão e da disciplina. Servir 2007; 55:11-20.

24. Kales HC, Kamholz BA, Visnic SG, Blow F. Recorded delirium in a national sample of elderly inpatients: potential implications for recognition. J Geriatr Psychiatr Neurol 2003; 16(1):32-8.

Received: Mar. $5^{\text {th }} 2010$ Accepted: Nov. 22 2010 